\title{
Biosynthesis of Silver Nanoparticles using Annona squamosa Leaf Extract with Synergistic Antibacterial Activity
}

\author{
R. LAKSHMI KALYANI, V. S. CHANDRA ${ }^{1}$, P. P. N. VIJAYKUMAR ${ }^{2}$, S. V. N. PAMMI ${ }^{3}$, M. RAJKUMAR, P. V. SWAMY* AND \\ K. V. R. MURTHY4* \\ Department of Pharmaceutics, Shri Vishnu College of Pharmacy, Vishnupur, Bhimavaram-534 202, ${ }^{1}$ Department of Humanities \\ and Basic Sciences (Physics), Godavari Institute of Engineering and Technology (Autonomous), Rajahmundry-533 296, \\ ${ }^{2}$ Advanced Analytical Laboratory, Andhra University, Visakhapatnam-530 003, ${ }^{3}$ Department of Materials Science and \\ Engineering, Chungnam National University, Daeduk Science Town, 34134, Daejeon, Republic of Korea, ${ }^{4} \mathrm{~A} . U$. College of \\ Pharmaceutical Sciences, Andhra University, Visakhapatnam-530 003, India
}

\section{Kalyani et al.: Synergetic Antibacterial Effect of Biosynthesized Silver Nanoparticles}

In the era of increased prevalence of bacterial resistance and outbreak of resistant infectious diseases, it is essential to develop effective therapeutic strategies towards multi-drug resistant pathogens. In this scenario, silver nanoparticles were tailored using Annona squamosa leaf extract and evaluated using various characterization techniques such as high-performance thin-layer chromatography, UV/Vis, scanning electron microscopy, X-ray powder diffraction, and Fourier-transform infrared spectroscopy. The synthesized AgNPs were assessed for antibacterial activity towards various Gram-positive and Gram-negative bacteria. In addition, the pharmacodynamic interaction of green synthesized AgNPs was assessed with gentamicin towards various bacteria as a novel adjuvant protocol, which revealed the remarkable antibacterial effect in comparison with AgNPs, or gentamicin alone. The superior biological activity was attributed to metabolites in plant extract, synthetic strategy of ultra-small AgNPs and synergistic effect of nano antibiotics.

Key words: Multi-drug resistance, silver nanoparticles, gentamicin, antibacterial activity, synergy

Nanotechnology attains considerable attention in pharmaceutical world to open new pathways that are capable of overcoming resistance mechanisms of bacteria ${ }^{[1]}$. Hospital acquired infections has become a cosmopolitan problem with reported resistance to all known classes of antibiotics ${ }^{[2]}$. Many adjuvant therapies have developed by the physicians and researchers to deal with multi-drug resistant bacteria but hampered due to exhibition of broad-spectrum action, drug-drug interactions, extended resistance mechanisms and incompatible pharmacodynamic and pharmacokinetic profiles $^{[3]}$. In pharmaceutical research, nano-scaled structures endeavor various theragnostic applications in a cost effective approach in terms of drug discovery, designing and delivery techniques ${ }^{[4,5]}$. Metals are known to be antibacterial since ancient times before any conventional antibiotics discovered. Nanotechnology employs metals as inorganic nanoparticles (NPs) that show their pleiotropic effect in targeting bacterial cellular process. Metallic NPs exhibit absolutely novel characteristics in comparison with bulk metals in terms

*Address for correspondence E-mail: vspadavala@svcp.edu.in

November-December 2019 of antibacterial, antioxidant, anticancer properties with less toxicity ${ }^{[6-8]}$. Synthesizing NPs through physical and chemical methods are capital and labor intensive with the involvement of non-polar solvents and toxic chemicals (capping and reducing agents) that are likely to induce toxicity issues ${ }^{[9,10]}$. Therefore, in recent times, an ecofriendly and bio-compatible method emerged with involvement of microorganisms and plants as environmentally sociable reducing and capping agents to reduce toxicity issues ${ }^{[11,12]}$. Though microbial-based synthesis have proven to be the potential bio-factories in nanoparticle synthesis, due to the complexity in isolating and culturing of microbes, plants and plant parts play a vital role in biological synthesis ${ }^{[13,14]}$. Phytosynthesis of NPs offers rapid, stable and easily scalable process

This is an open access article distributed under the terms of the Creative Commons Attribution-NonCommercial-ShareAlike 3.0 License, which allows others to remix, tweak, and build upon the work non-commercially, as long as the author is credited and the new creations are licensed under the identical terms

Accepted 24 September 2019

Revised 21 June 2019

Received 24 January 2019

Indian J Pharm Sci 2019;81(6):1036-1044 
in a cost effective way due to the presence of a wide range of metabolites. Therefore, phytosynthetic inorganic NPs encompass metals in nano form with incorporation of plant metabolites to provide effective antibacterial action in a safer approach ${ }^{[15]}$. Though inorganic NPs show excellent antibacterial action, with vast research under consideration, researchers cannot ignore antibiotics that have contributed to a better quality of life. Thus, combinational approach of green inorganic NPs with antibiotics can be an assurance for non-toxic and more effective bactericidal action as bacteria cannot develop instant mechanisms to attain resistance to the multi-mode mechanistic antibacterial approach $^{[16-19]}$. In present study, silver (Ag) NPs are prepared and investigated as silver have shown its proficiency in dealings with biological systems and biomedical applications ${ }^{[13,15]}$. Annona squamosa leaves are preferred for the reduction process in synthesizing NPs, as they possess interesting medicinal properties along with treatment of wound and urinary tract infections ${ }^{[20]}$. In addition to bactericidal action of $\mathrm{Ag}$ and A. squamosa metabolites, gentamicin is elected in this adjuvant therapy as it holds unique properties in bactericidal action by inhibiting bacterial protein synthesis $^{[21]}$. As gentamicin attain resistance to many Gram-negative and Gram-positive strains, this adjuvant therapy of gentamicin with $A$. squamosaAgNPs was tested on different Gram-positive and negative bacterial strains in comparison with AgNPs and gentamicin alone.

\section{MATERIALS AND METHODS}

A. squamosa leaves were collected from the surroundings of Andhra University, Visakhapatnam, Andhra Pradesh, India, which were authenticated in the Botany department and a voucher specimen was kept in the herbarium (no. 22290). All reagents used in this study were of analytical grade and were procured from Sigma Aldrich, Pune, India. Staphylococcus aureus NCIM 2079, Pseudomonas aeruginosa NCIM 5514, Acinetobacter baumannii NCIM 5654, Proteus vulgaris NCIM 2813 were purchased from the National Collection of Industrial Microorganisms (NCIM), NCL, Pune, India. Enterococcus faecium MTCC5153 was obtained from the Microbial type culture collection, Chandigarh, India. Agar medium and gentamicin was procured from HiMedia, Mumbai, India.

\section{Preparation of $A$. squamosa leaf extract:}

Fresh A. squamosa leaves were employed to extract the active constituents. The leaves were thoroughly rinsed with tap water and then with double-distilled water to get rid of dust particles. The leaves were dried in shade and made into a coarse powder. A. squamosa leaf powder $(5 \mathrm{~g})$ was mixed with $100 \mathrm{ml}$ of distilled water and subjected to boiling at $60^{\circ}$ in a water bath for $10 \mathrm{~min}$. The mixture was cooled and filtered through a muslin cloth followed by Whatman no. 1 filter paper. Later, the filtrate was centrifuged at $10000 \mathrm{rpm}$ for $10 \mathrm{~min}$. The supernatant was collected and autoclaved for $15 \mathrm{~min}$ at $121^{\circ}$ under $15 \mathrm{lbs}$ pressure. A clear solution with greenish yellow color was collected and stored in screw-capped bottles at $4-8^{\circ}$ and used as a reducing agent in AgNP synthesis.

\section{Phytosynthesis of AgNPs:}

To synthesize AgNPs, the conditions were optimized by fixing 2 of the components among $\mathrm{Ag}$ salt concentration, time and plant extract and by altering one component in each experiment. The optimized condition was predicted through the color change and also confirmed by periodic monitoring of UV/Vis spectra. $\mathrm{AgNO}_{3}(\geq 99.5 \%$ purity) solution and aqueous extract of appropriate concentrations were prepared using double-distilled water. The reduction of $\mathrm{Ag}$ ions from $\mathrm{AgNO}_{3}$ to $\mathrm{Ag}$ was detected through a color change of the solution due to the reducing capability of metabolites in the extract. The nanoparticle dispersion was subjected to centrifugation at $10000 \mathrm{rpm}$ at $4^{\circ}$ for $15 \mathrm{~min}$. The obtained pellets were re-dispersed in methanol and re-centrifuged. The pellet was again washed with deionized water to remove any unbound extract or impurities. The obtained NPs were dried at $80^{\circ}$ in a hot air oven. The obtained powder concentrate of Ag NPs was stored at $4^{\circ}$ in air tight containers for further characterization, and antibacterial studies.

\section{Characterization of AgNPs:}

The chromatographic fingerprint profile of $A$. squamosa leaf extract was studied using high-performance thinlayer chromatography (HPTLC) analysis Camag Linomat 5, Linomat5 211497 instrument programmed with WIN CATS software to investigate the phytochemical profile. The synthesized AgNPs were characterized by UV/Vis (Shimadzu UV/VIS 2450) in the wavelength range of $300-700 \mathrm{~nm}$ to measure the biophysical properties. scanning electron microscope (SEM)-EDX (Jeol JSM-6610-LV- with Oxford EDS) analysis was performed at an accelerated voltage of $200 \mathrm{kV}$ to elucidate morphology, structure and composition. The X-ray diffraction (PANalytical: XPERT-PRO) was operated at $40 \mathrm{kv}$ and $30 \mathrm{~mA}$ 
under $\mathrm{Cu} \mathrm{K} \alpha$ radiations $\left(\lambda=1.54060^{\circ} \mathrm{A}\right)$ using nickel monochromator at a range of $2 \Theta$ from $10^{\circ}$ to $80^{\circ}$ to examine the crystalline nature of synthesized AgNPs. Fourier-transform infrared spectroscopy (FTIR, Shimadzu FT-IR 21) analysis of A. squamosa leaf extract and $A$. squamosa-AgNPs was evaluated using KBR pellet in a wavelength range of 4000 to $400 \mathrm{~cm}^{-1}$ at a resolution of $4 \mathrm{~cm}^{-1}$ to detect the possible functional groups (biomolecules) responsible for AgNPs formation.

\section{Antibacterial adjuvant assay:}

Antibacterial adjuvant was tested on 5 bacterial strains namely, $S$. aureus, A. baumannii, $P$. aeruginosa, $E$. faecium and $P$. vulgaris. The bacterial strains were placed on sterile Mueller Hinton agar slants at $4^{\circ}$. Each bacterial strain was placed in $50 \mathrm{ml}$ of sterile nutrient broth in a $100 \mathrm{ml}$ conical flask and incubated for $24 \mathrm{~h}$ to activate the bacterial strains. The bacterial inoculums were standardized with respect to McFarland standard no. 0.5 with $1.5 \times 10^{8} \mathrm{CFU} / \mathrm{ml}$ bacterial density. The bacterial susceptibility with $A$. squamosa-AgNPs, gentamicin, and A. squamosa-AgNPs in combination with gentamicin was tested on bacterial strains by agar well diffusion method.

Twenty five milliliters of $\mathrm{ml}$ of MHA was mixed with $500 \mu \mathrm{l}$ of test cultures, poured in the petri plate and left for solidification. Four wells of $6 \mathrm{~mm}$ each were made in each plate with the help of sterile cork borer. The minimum inhibitory concentration (MIC) of A. squamosa-AgNPs was estimated using two-fold serial dilutions with in a concentration range of 3.125 to $50 \mu \mathrm{g} / \mathrm{ml}$. The wells were loaded with $100 \mu \mathrm{l}$ of AgNPs $(25 \mu \mathrm{g} / \mathrm{ml}), 100 \mu \mathrm{l}$ gentamicin $(50 \mu \mathrm{g} / \mathrm{ml})$, and combination of gentamicin with $A$. squamosa-AgNPs each at a quantity of $50 \mu$ in dimethyl sulfoxide (DMSO; $37.5 \mu \mathrm{g} / \mathrm{ml}$ ) and incubated for $24 \mathrm{~h}$ at $37^{\circ}$ using DMSO as control. The zone of inhibition (ZOI) was measured (in $\mathrm{mm}$ ) by repeating the experimentation thrice and the $\%$ of area increase with adjuvancy was calculated using the formula ${ }^{[19]}$, ZOI of (AgNPs+antibiotic) ${ }^{2}-\mathrm{ZOI}$ of antibiotic $2 / Z O I$ of antibiotic ${ }^{2} \times 100$.

\section{Statistical analysis:}

The one-way analysis of variance (ANOVA) method was used the ZOI of each nanoparticle or gentamicin against each bacteria used. In order to establish the statistical significance, the values were assessed by using GraphPad Prism version 5.03 (GraphPad Software, Inc. CA, USA trail version). All the experiments were done in triplicate and the results as expressed as mean $\pm \mathrm{SD}$, $\mathrm{n}=3$, and the statistical significance was accepted at a level of $p<0.05$ for all the combinational effect of metallic NPs with gentamicin, where null hypothesis was rejected and alternate hypothesis was accepted. Hence, there was a significant difference between the individual nanoparticle/gentamicin antibacterial activity and in the combinational antibacterial activity. Hence, combinational therapy with NPs is more effective than the individual treatment with gentamicin.

\section{RESULTS AND DISCUSSION}

Preliminary screening was performed to detect the presence of numerous phytochemicals present in A. squamosa leaf extract using reagent tests. The phytochemical screening revealed the presence of various primary and secondary metabolites with significant biological value. HPTLC is an updated qualitative analytic tool for identification of biomolecules in the sample with the display of more resolved spots and effective analysis of compounds. In the current study, the HPTLC profile of A. squamosa leaf extract was carried out with petroleum ether and chloroform solvents separately using definite solvent ratios and analyzed before and after spray treatment (methanol:sulphuric acid) under UV wavelength, 254 and $366 \mathrm{~nm}$, respectively. The HPTLC analysis reveals the diverse phytochemicals present in A. squamosa leaf extract, which might be a valuable source for the effective synthesis of AgNPs and enhancement in biological activity. In addition, A. squamosa leaf extract reported to have numerous phytochemicals such as alkaloids, flavonoids, phenols, proteins, carbohydrates, glycosides, saponins, tannins and the same was confirmed in this study by phytochemical analysis ${ }^{[22-24]}$. Among which, ferric chloride test detected the presence of phenols by developing bluish green instantly after addition of ferric chloride reagent and lead acetate test proved the presence of phenolic compounds by forming bulky white precipitate, which confirmed abundant presence of phenols. Moreover, phenols have high potential to act as reducing and capping agent in the preparation of stable NPs as evident from recent reports ${ }^{[25,26]}$. Thus, phenols present in A. squamosa leaf extract might play a vital role for the formation of AgNPs.

The AgNPs formation was detected through color change from colorless silver nitrate to dark yellow color and then finally to colloidal brown color within few hours after mixing the leaf extracts solution (fig. 1). 

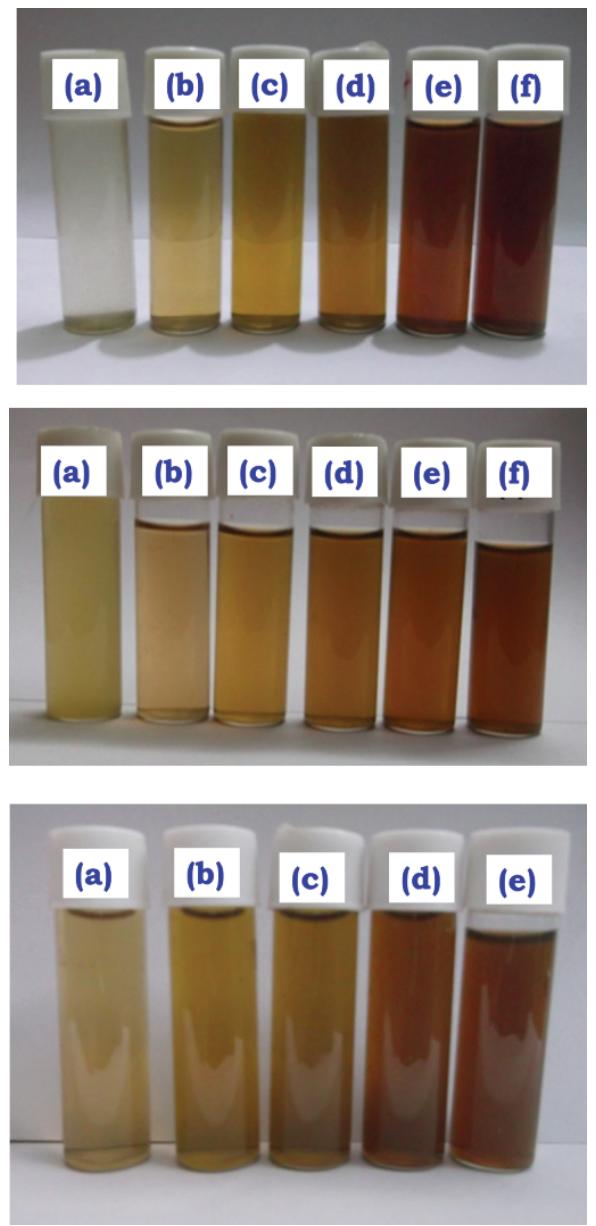

Fig. 1: Color change variations of the A. squamosa-AgNP solutions with different optimization conditions

The color change of the medium could be due to the excitation of surface plasmon vibrations ${ }^{[27]}$. In order to obtain stable and uniform AgNPs formation, the various physicochemical conditions were optimized such as concentration of precursor solution and leaf extract and reaction time as these factors can significantly influence the size, shape, and morphology ${ }^{[13]}$. The optimization process of Ag nanoparticle synthesis was examined analytically via UV/Vis spectroscopy as shown in fig. 2. In aqueous solution, AgNPs exhibit strong surface plasmon resonance around $430 \mathrm{~nm}$ for the formation of well-stabilized AgNPs ${ }^{[28]}$. Based on the earlier reported parameters for optimization of NPs, the UV/Vis peak with high intensity and low bandwidth were considered for the optimization of $\mathrm{NPs}^{[13,27,29,30]}$.

For optimizing condition for AgNPs, temperature of reaction and $\mathrm{pH}$ are not under the focus of study, as the preparation of AgNPs was aimed not to employ any external energy or agents. High temperature synthesis readily form NPs but with large size ${ }^{[31]}$. Moreover, at high temperatures biological moieties from the extract may be lost which may rise agglomeration.
Thus, the present investigation aimed at controlled green synthesis at room temperature to synthesize small size stable AgNPs. $\mathrm{pH}$ can be maintained at the range of 4-6 in case of green synthesis ${ }^{[32]}$. Initially, the effect of the silver nitrate precursor solution on the formation of AgNPs was studied systematically by changing the molar concentration of silver nitrate
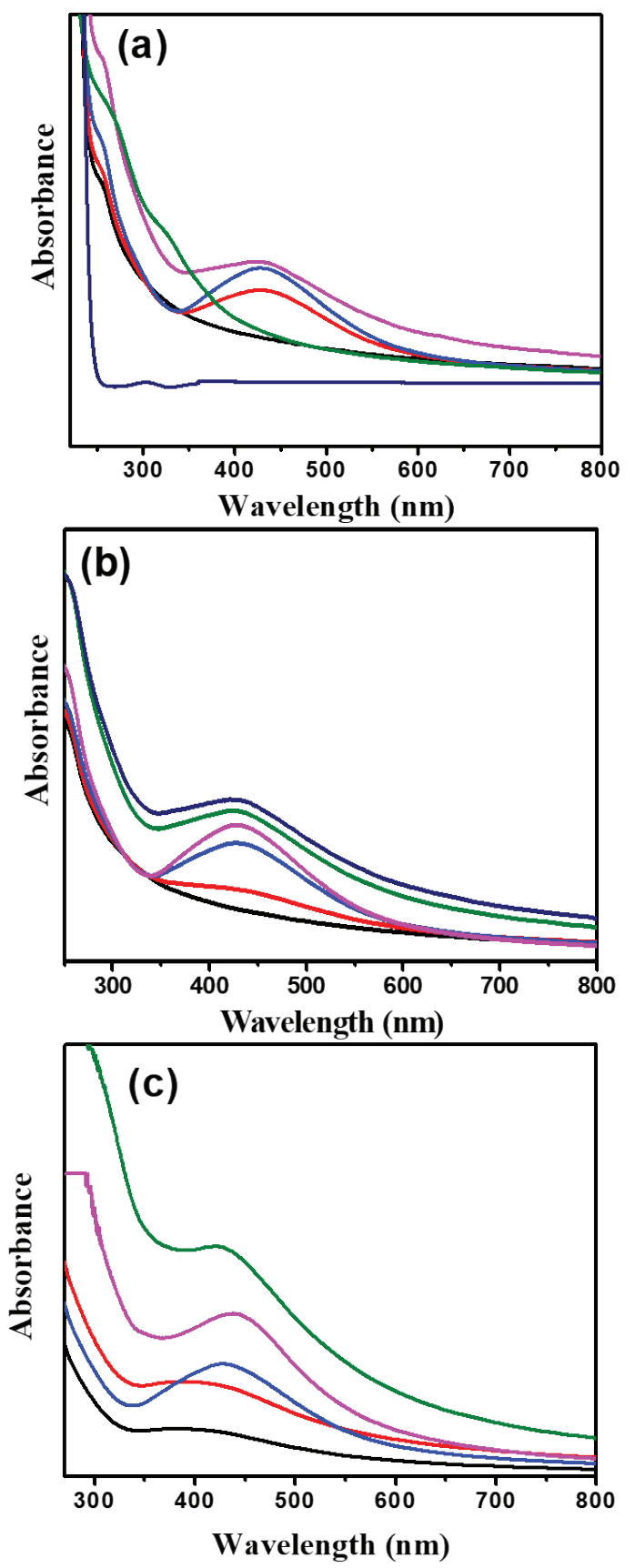

Fig. 2: Absorption spectra of AgNPs obtained from various optimizing parameters

(a) Effect of Ag ion concentration, (-) $2 \mathrm{mM}$, (-) $5 \mathrm{mM}$, (—) $10 \mathrm{mM},(-) 50 \mathrm{mM}$, (-) leaf extract, (-) $\mathrm{AgNo}_{3}$; (b) different time intervals, (-) immediate, (-) $30 \mathrm{~min}$, (—) $1 \mathrm{~h},(-) 2 \mathrm{~h},(-) 4 \mathrm{~h},(-) 8 \mathrm{~h}$; (c) different volume of leaf extract, (-) $1 \mathrm{ml},(-) 3 \mathrm{ml},(-) 5 \mathrm{ml}$, (—) $7 \mathrm{ml},(\longrightarrow) 10 \mathrm{ml}$ 
in $10 \mathrm{ml}$ by fixing the volume of extract as $3 \mathrm{ml}$ and $1 \mathrm{~h}$ as the reaction time. No absorption spectrum was observed for $0.002 \mathrm{M}$ concentration of silver nitrate (fig. 2a). With increase in metal precursor concentration $(0.005 \mathrm{M})$, the absorption band was observed around $430 \mathrm{~nm}$. At $0.01 \mathrm{M}$ concentration, optimum intensity peak with lower band width was noticed. The enhancement in bandwidth was detected with increase in the metal precursor concentration $(0.01$ to $0.05 \mathrm{M})$. From the earlier reports, enhanced band width infers large sized NPs/agglomeration. Therefore, the metal precursor concentration was optimized as $0.01 \mathrm{M}$, as the lower absorption bandwidth reflects the formation of uniformly small sized $\mathrm{AgNPs}^{[13,29,30]}$. Reaction time is a crucial factor to obtain the mono dispersed small NPs. By fixing the metal precursor concentration $(0.01 \mathrm{M})$ and volume of leaf extract $(3 \mathrm{ml})$, reaction time was monitored by UV/Vis spectra. With an increase in reaction time, the absorbance intensity was increased with reduced absorption width simultaneously until $2 \mathrm{~h}$. On further increase in reaction time from 2 to $8 \mathrm{~h}$, enlarged width of absorption spectra was seen $^{[13,29,30]}$ (fig. 2b), indicating enhancement of particle size and/or agglomeration and hence reaction time was optimized as $2 \mathrm{~h}$. Further optimization was focused on $A$. squamosa leaf extract volume, by fixing metal precursor concentration $(0.01 \mathrm{M})$ and reaction time $2 \mathrm{~h}$. On rise of $A$. squamosa leaf extract volume to $5 \mathrm{ml}$, absorption band width was reduced with increased intensity was observed, which indicated small sized NPs with high yield ${ }^{[27,13,29,30]}$. By further increasing the volume to $10 \mathrm{ml}$, the absorption band width was increased (fig. 2c), representing larger size of AgNPs and/or agglomeration of particles as confirmed from previous reports ${ }^{[27,13,29,30]}$. Therefore, $5 \mathrm{ml}$ was considered as the desired volume for preparation of NPs without agglomeration.

To examine the size, surface morphology and crystalline nature of the synthesized A. squamosaAgNPs, XRD, and SEM analysis was performed. The SEM image exhibited larger clusters with numerous small particles, which might be due to the evaporation of solvent during SEM sample preparation (fig. 3a). The energy-dispersive X-ray (EDX) spectra of A. squamosa-AgNPs were examined at an accelerating voltage $(15 \mathrm{kv})$, which displayed $91.36 \%$ yield (weight \%) of elemental Ag in L line (fig. 3b). The XRD pattern of $A$. squamosa leaf extract mediated synthesis of AgNPs has been evaluated in the range of $20-90^{\circ}$
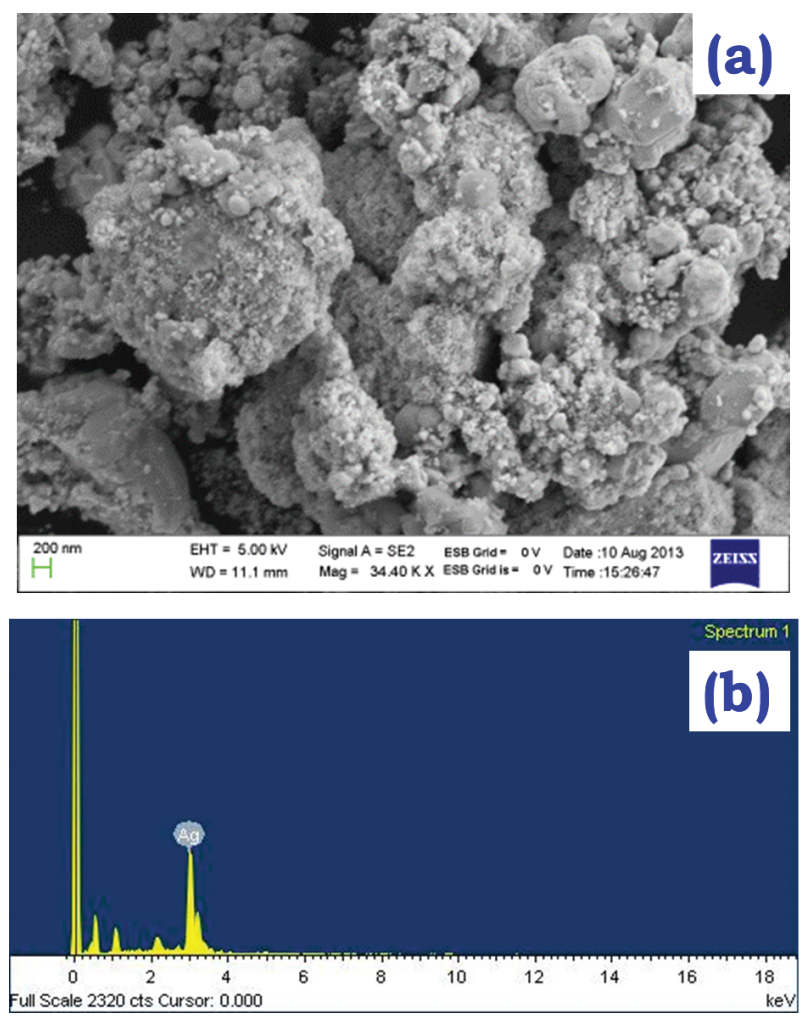

Fig. 3: (a) SEM and (b) EDS analysis of green synthesized A. squamosa-AgNPs

and high-intensity peaks of $A$. squamosa-AgNPs were detected at $38,44,64,78$ and $81^{\circ}$ that corresponds to Bragg reflections (111), (200), (211), (311), and (222), respectively (fig. 4a). These peaks represent the exact peak positions of the silver face center cubic lattice structure. There are no additional reflections observed indicating absence of impurities or amorphous organic phase. From the XRD pattern, the average crystallite size was calculated by the Debye-Scherer Eqn. and Williamson-Hall plot and was approximately 9 and $6.6 \mathrm{~nm}$, respectively.

FTIR analysis was employed to identify the biomolecules that are responsible for silver ion reduction and capping of AgNPs, which leads to efficient stabilization for the biosynthetic process of AgNPs. The FTIR spectra of $A$. squamosa leaf extract and A. squamosa-AgNPs were depicted in fig. $4 \mathrm{~b}$ and Table 1. The FTIR spectra of $A$. squamosa leaf extract have dominant absorption bands at 3348, 2903, 2349, 1441, 1251, 1050 and $663 \mathrm{~cm}^{-1}$. These absorption bands were assigned to $\mathrm{O}-\mathrm{H}, \mathrm{C}-\mathrm{H}$ stretching, C-C stretching vibrations, $\mathrm{O}-\mathrm{H}$ bend/amide, $\mathrm{C}-\mathrm{N}$ stretching, $\mathrm{C}-\mathrm{OH}$ vibrations and $\mathrm{N}-\mathrm{H}$ (amines) respectively ${ }^{[33-35]}$. The absorption bands with low intensity at 1734 and $1386 \mathrm{~cm}^{-1}$ denote $\mathrm{C}$-O stretching vibrations (carboxylic acid $)^{[36]}$. 
TABLE 1: FTIR SPECTRA OF A. SQUAMOSA LEAF EXTRACT AND AgNP

\begin{tabular}{lccc}
\hline Functional Group & $\begin{array}{c}\text { Characteristic absorption } \\
\text { band }\left(\mathrm{cm}^{-1}\right)\end{array}$ & $\begin{array}{c}\text { Absorption bands in AS leaf } \\
\text { extract }\left(\mathbf{c m}^{-1}\right)\end{array}$ & $\begin{array}{c}\text { Absorption bands in AgNPs } \\
\left(\mathbf{c m}^{-1}\right)\end{array}$ \\
\hline Water OH stretch & $3700-3100$ & & \\
Alcohol OH stretch & $3600-3200$ & 3348 & 3469 \\
Carboxylic acid OH stretch & $3600-2500$ & & \\
N-H stretch & $3500-3350$ & 2903 & 2899 \\
-C-H aldehyde & $2900-2800$ & & \\
-C-H stretch & $2950-2840$ & 2349 & \\
C=C- stretch & $2260-2100$ & 1514,1608 & 1553,1639 \\
C=O amide & $1700-1500$ & 1441 & 1410 \\
O-H bend, amide III & $1480-1315$ & 1050 & 1046 \\
-CO groups & $1050-1150$ & &
\end{tabular}
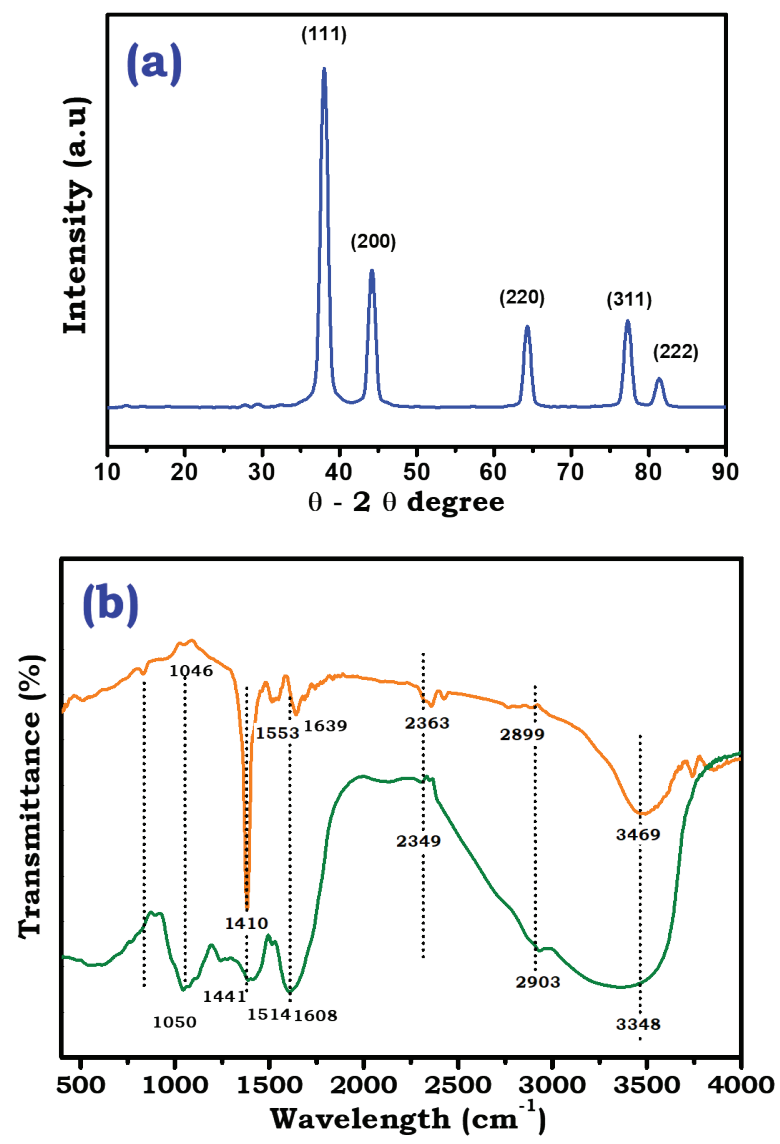

Fig. 4: (a) XRD Pattern (b) FTIR spectra of green synthesized A. squamosa-AgNPs

(—) A. squamosa-AgNPs, (-) A. squamosa leaf extract

The FTIR spectra of AgNPs exhibited bands around 1100, 1400, 1636, 2132 and $3300 \mathrm{~cm}^{-1}$. The most prominentband at $1410 \mathrm{~cm}^{-1}$ attributed to COO stretching vibration $^{[13,35]}$. The strong absorption band around $3348 \mathrm{~cm}^{-1}$ representsed $\mathrm{O}-\mathrm{H}$, which corresponded to $\mathrm{O}-\mathrm{H}$ stretching of alcohol and phenolic compounds or stretching of the $-\mathrm{NH}$ band of an amino group. The band at $1640 \mathrm{~cm}^{-1}$ is due to stretching vibration of $-\mathrm{CO}$ amide groups in the ketones, aldehydes and carboxylic



Fig. 5: Zeta potential distribution of green synthesized A. squamosa-AgNPs

Zeta potential: $-\mathbf{2 0 . 5} \mathrm{mV}$

acids $^{[37]}$. The bands at 1083 and $1046 \mathrm{~cm}^{-1}$ indicated the presence of $-\mathrm{CO}$ groups. The presence of a weak band at $2980 \mathrm{~cm}^{-1}$ is related to aliphatic C-H stretching in methyl and methylene groups ${ }^{[35,37]}$. The similarity of bands in both the A. squamosa leaf extract and A. squamosa-AgNPs (Table 1), might be due to capped biomolecules on to the surface of AgNPs.

The zeta potential measurement of AgNPs exhibited the surface charges of the particles and exhibited a value of $-20 \mathrm{mV}$ (fig. 5), suggesting higher stability of AgNPs. The large negative potential value might be attributed to the capping of phenols present in the leaf extract of $A$. squamosa.

In the emergent era to find the novel antimicrobials, adjuvant therapy of green synthesized NPs with an antibiotic seems to be a viable option to treat antibioticresistant strains ${ }^{[16-19]}$. All the bacterial experimentation was done in a laminar air flow chamber under sterile conditions. The antimicrobial activity of A. squamosa-AgNPs $(25 \mu \mathrm{g} / \mathrm{ml})$, gentamicin $(50 \mu \mathrm{g} / \mathrm{ml})$ and gentamicin A. squamosa-AgNPs (50 $\mu \mathrm{l}$ of each 
TABLE 2: SYNERGETIC ACTIVITY OF A. SQUAMOSA-AgNPS AND GENTAMICIN AGAINST BACTERIAL PATHOGENS

\begin{tabular}{lcccc}
\hline Bacterial strain & $\begin{array}{c}\text { A. squamosa- AgNPs } \\
(\mathbf{2 5} \boldsymbol{\mu g} / \mathrm{ml})\end{array}$ & $\begin{array}{c}\text { Gentamicin }(50 \mu \mathrm{g} / \mathrm{ml}) \\
{[\mathrm{A}]}\end{array}$ & $\begin{array}{c}\text { A. squamosa- } \\
\text { AgNPs+gentamicin }[\mathrm{B}]\end{array}$ & $\begin{array}{c}\text { \% increase in area } \\
\left(\mathrm{B}^{2}-\mathrm{A}^{2} / \mathrm{A}^{2}\right) \times 100\end{array}$ \\
\hline $\begin{array}{l}\text { Zseudomanas } \\
\text { aeruginosa }\end{array}$ & $15.24 \pm 0.12$ & $17.54 \pm 0.17$ & $20.73 \pm 0.15$ & 39.68 \\
$\begin{array}{l}\text { Acinetobacter } \\
\text { baumannii }\end{array}$ & $15.8 \pm 0.25$ & $18.31 \pm 0.15$ & $23.32 \pm 0.09$ & 62.21 \\
Staphylococcus aureus & $16.25 \pm 0.17$ & $20.28 \pm 0.23$ & $22.067 \pm 0.12$ & 18 \\
Enterococcus faecium & $20.42 \pm 0.15$ & $22.77 \pm 0.21$ & $23.85 \pm 0.15$ & 9.7 \\
Proteus vulgaris & $19.45 \pm 0.22$ & $21.66 \pm 0.12$ & $24.93 \pm 0.18$ & 32.47 \\
\hline
\end{tabular}

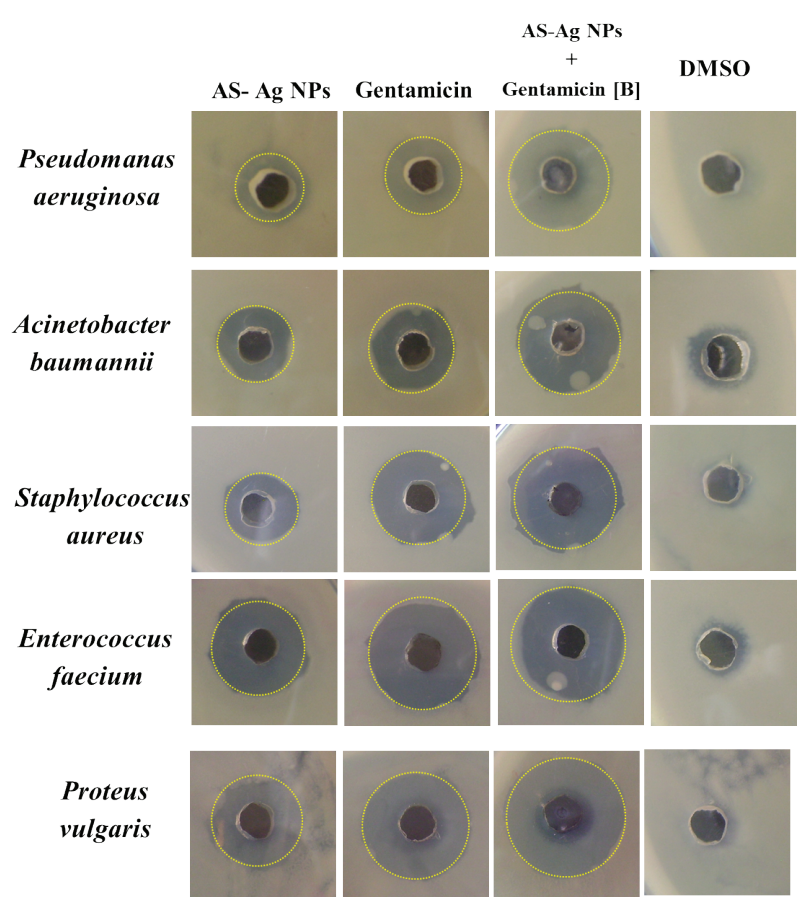

Fig. 6: Synergetic antibacterial activity of AgNP against wound/ burn infection causing bacteria

sample) were tested against $S$. aureus, A. baumannii, P. aeruginosa, E. faecium, and P. vulgaris.

There were reports stating that some of these bacterial strains attained considerable resistance to gentamicin ${ }^{[21]}$. The MIC of A. squamosa-AgNPs in case of $S$. aureus, A. baumannii, $P$. aeruginosa, E. faecium, $P$. vulgaris were $3.125,3.125,3.125,6.25$, and $3.125 \mu \mathrm{g} / \mathrm{ml}$ respectively and the ZOI was increased in a dose-dependent manner. The green synthesized AgNPs have shown considerable ZOI even at the minimum concentration range towards all the tested bacteria which proves their effective activity as antimicrobial agent. A. squamosa-AgNPs $(25 \mu \mathrm{g} / \mathrm{ml})$ have shown almost equal antibacterial activity to that of gentamicin $(50 \mu \mathrm{g} / \mathrm{ml})$ as shown in fig. 6 .

The mechanism behind the combination of nanoparticle and antibiotic is still unclear but with assumptions such as covalent bonding between the nanoparticle and sulfhydryl groups (-SH) groups in antibiotics or due to hydrophobic interactions or because of electrostatic interactions between positively charged zone in antibiotics and negatively charged particle ${ }^{[20]}$. The combination of antibiotic with NPs may alter the properties of NPs with enhanced effects as described in a report ${ }^{[38]}$.

In the combination assay of $A$. squamosa-AgNPs with gentamicin, it has the combination assay of A. squamosa-AgNPs with gentamicin, it has shown significant area increase of $39.68,62.21,18,9.7$, $32.47 \%$, respectively towards $S$. aureus, A. baumannii, $P$. aeruginosa, E. faecium, $P$. vulgaris. The percent increase in area is an evidence of synergistic action, which is attributed from combinational effect of green synthesized AgNPs and the antibiotic as shown in Table 2. It is interesting to note that this combination showed synergistic effect towards all the tested microorganisms without any indifferent or negative activity. On observation, it is clear that this adjuvant technique has shown greater effect on Gram-negative bacteria than Gram-positive bacteria. The difference in activity between the Gram strains might be due to the thin peptidoglycan layer in case of Gram-negative strains, which is readily feasible for penetration of the nanoparticle antibiotic combination ${ }^{[13,16]}$. However, the $\%$ increase in zones of inhibition of Gram-positive bacteria is also significant, which might be due to ultrasmall size of synthesized $A$. squamosa-AgNPs that can penetrate even through thick peptidoglycan layer. The probable mechanism for antibacterial activity by these adjuvant combinations is still under preliminary investigation and possibly due to adherence and penetration in to the bacterial cell wall and interaction with sulphur and phosphorous groups of bacterial DNA ensuing bactericidal action ${ }^{[17-19]}$. Due to green chemistry approach in nano field, it's an assurance that bio-synthesized NPs are usually biocompatible than that of chemically synthesized $\mathrm{NPs}^{[39-42]}$. 
In conclusion, AgNPs of ultra-small size with crystalline nature were prepared through an ecofriendly process using A. squamosa leaf extract as a reducing agent. In spite of potential antibacterial activity displayed by bio-synthesized AgNPs, with adjuvant combination of green synthesized NPs and conventional antibiotics there was a vast improvement in antibacterial activity in comparison with antibiotics in a resistance free and toxic free manner due to the multimode antibacterial activity, which was well demonstrated with significant fold percent increase in antibacterial activity. With the fascinating green nano chemistry in combination with antibiotics, the resistance challenge can be accepted by the pharmaceutical world. Further studies on evaluation of exact mechanism of $A$. squamosa-AgNPs for antibacterial activity need to be evaluated in future research.

\section{Acknowledgements:}

We acknowledge Shri Vishnu College of Pharmacy for guidance and support in carrying out research and writing this article. We also acknowledge DST-Purse, Andhra University for characterization techniques. Authors thank Prof. S.B. Padaal, Botany Department for authenticating the plant material.

\section{Conflicts of interest:}

The authors report no conflicts of interest. The authors alone are responsible for the content and writing of this article.

\section{REFERENCES}

1. Emerich DF, Thanos CG. Nanotechnology and medicine. Expert Opin Biol Ther 2003;3:655-63.

2. Harbottle H, Thakur S, Zhao S, White DG. Genetics of antimicrobial resistance. Anim Biotechnol 2006;17:111-24.

3. Courtney CM, Goodman SM, McDaniel JA, Madinger NE, Chatterjee A, Nagpal P. Photoexcited quantum dots for killing multidrug-resistantbacteria. Nat Mater 2016;15(5):529-34.

4. Vasir JK, Reddy MK, Labhasetwar V. Nanosystems in drug targeting: opportunities and challenges. Curr Nanosci 2005;1(1):47-64.

5. Zaidi S, Misba L, Khan AU. Nano-therapeutics: A revolution in infection control in post antibiotic era. Nanomedicine 2017;13:2281-301.

6. Barve MG, Mashru M, Jagtap C, Patgiri BJ, Prajapati PK. Therapeutic potentials of metals in ancient India: A review through Charaka Samhita. J Ayu Integr Med 2011;2(2):55-63.

7. Qayyum S, Khan AU. Nanoparticles vs. biofilms: a battle against another paradigm of antibiotic resistance. Med Chem Commun 2016;7(8):1479-98.

8. Allahverdiyev AM, Kon KV, Abamor ES, Bagirova M, Rafailovich M. Coping with antibiotic resistance: combining nanoparticles with antibiotics and other antimicrobial agents. Expert Rev Anti Infect Ther 2011;9(11):1035-52.
9. Khan I, Saeed K, Khan I. Nanoparticles: Properties, applications and toxicities. Arab J Chem 2019;12(7):908-31.

10. Schrofel A, Kratosova G, Safarik I, Safarikova M, Raska I, Shor LM. Applications of biosynthesized metallic nanoparticles- a review. Acta Biomater 2014;10(10):4023-42.

11. Asmathunisha N, Kathiresan K. A review on biosynthesis of nanoparticles by marine organisms. Coll Surf B: Bionterf 2013;103:283-7.

12. Singh P, Kim YJ, Zhang D, Yang DC. Biological Synthesis of Nanoparticles from Plants and Microorganisms. Trends Biotechnol 2016;34(7):588-99.

13. Pallela PNVK, Ummey S, Ruddaraju LK, Pammi SVN, Yoon SG. Ultra-Small, mono dispersed green synthesized silver nanoparticles using aqueous extract of Sida cordifolia plant and investigation of antibacterial activity. Microb Pathog 2018;124:63-69.

14. Raghavan KV, Kumar TA. Plant-mediated biosynthesis of metallic nanoparticles: A review of literature, factors affecting synthesis, characterization techniques and applications. J Environ Chem Eng 2017;5(5):4866-83.

15. Acharyulu NPS, Kiran P, Madhu, Pratap K, Kalyani RL, Pammi SVN. Room Temperature Synthesis and Evaluation of Antibacterial Activity of Silver Nanoparticles Using Phyllanthus amarus leaf extract. J Bionanosci 2014;8(3):190-4.

16. Ghosh S, Patil S, Ahire M, Kitture R, Kale S, Pardesi K, et al. Synthesis of silver nanoparticles using Dioscorea bulbifera tuber extract and evalution of its synergistic potential in combination with antimicrobial agents. Int $\mathrm{J}$ Nanomed 2012;7:483-96

17. Patra JK, Baek KH. Antibacterial Activity and Synergistic Antibacterial Potential of Biosynthesized Silver Nanoparticles against Foodborne Pathogenic Bacteria along with its Anticandidal and Antioxidant Effects. Front Microbiol 2017;8:167

18. Basker S. Synergistic Efficacy of Antibiotics and Silver Nanoparticles Synthesized from Eichhornia crassipes. Res Plant Biol 2016;6:01-5.

19. Fayaz AM, Balaji K, Girilal M, Yadav R, Kalaichelvan PT, Venketesan R. Biogenic synthesis of silver nanoparticles and their synergistic effect with antibiotics: a study against gram-positive and gram-negative bacteria. Nanomedicine 2010;6(1):103-09.

20. Simon KN, Santhoshkumar R, KumarNS. Phytochemical analysis and antimicrobial activities of Annona squamosa (L) leaf extracts. J Pharmacogn Phytochem 2016;5(4):128-31.

21. Syed B, Azmath P, Satish S. Biogenic nanoparticles bearing antibacterial activity and their synergistic effect with broad spectrum antibiotics: Emerging strategy to combat drug resistant pathogens. Saudi Pharm J 2017;25:44-51.

22. Varadharajan V, Janarthanan UV, Vijayalakshmi K. Physicochemical, phytochemical screening and profiling of secondary metabolites of Annona squamosa leaf extract. World J Pharmaceutical Res 2012;1(4):1143-64.

23. Gowdhami M, Sarkar BL, Ayyasamy PM. Screening of Phytochemicals and Antibacterial Activity Of Annona Squamosa Extracts. Inte J Pharm Sci Invent 2014;3(7):30-39.

24. Ruddaraju LK, Kumar VPPN, Pammi SVN, Veerabhadra SP, Kolapalli VRM. Synergetic antibacterial and anticarcinogenic effects of Annona squamosa leaf extract mediated silver nano particles. Mater Sci 2019;100:301-9.

25. Alegria E, Ribeiro A, Mendes M, Ferraria A, do Rego A, 
Pombeiro A. Effect of Phenolic Compounds on the Synthesis of Gold Nanoparticles and its Catalytic Activity in the Reduction of Nitro Compounds. Nanomaterials 2018;8(5):320.

26. Mohamad NAN, Arham NA, Jai J, Hadi A. Plant Extract as Reducing Agent in Synthesis of Metallic Nanoparticles: A Review. Adv Mater Res 2013;832:350-5.

27. Thirumurugan G, Veni VS, Ramachandran S, Rao JV, Dhanaraju MD. Superior wound healing effect of topically delivered silver nanoparticle formulation using eco-friendly potato plant pathogenic fungus: Synthesis and characterization. J Biomed Nanotechnol 2011;7(5):659-66.

28. El-Naggar NE, Hussein MH, El-Sawah AA. Phycobiliproteinmediated synthesis of biogenic silver nanoparticles, characterization, in vitro and in vivo assessment of anticancer activities. Sci Rep 2018;8(1):8925.

29. Mogensen KB, Kneipp K. Size-Dependent Shifts of Plasmon Resonance in Silver Nanoparticle Films Using Controlled Dissolution: Monitoring the Onset of Surface Screening Effects. J Phys Chem C 2014;118(48):28075-83.

30. Saion E, Gharibshahi E, Naghavi K. Size-Controlled and Optical Properties of Monodispersed Silver Nanoparticles Synthesized by the Radiolytic Reduction Method. Int J Mol Sci 2013;14(4):7880-96.

31. Karakoti AS, Munusamy P, Hostetler K, Kodali V, Kuchibhatla $\mathrm{S}$, Orr G, et al. Preparation and characterization challenges to understanding environmental and biological impacts of ceria nanoparticles. Surface Interface Anal 2012;44(8):882-9.

32. Patel P, Agarwal P, Kanawaria S, Kachhwaha S, Kothari SL. Plant-Based Synthesis of Silver Nanoparticles and Their Characterization. Nanotechnol Plant Sci 2015;271-88.

33. Gunalan S, Sivaraj R, Rajendran V. Green synthesized ZnO nanoparticles against bacterial and fungal pathogens. Progress Nat Sci 2012;22(6):693-700.

34. Bala N, Saha S, Chakraborty M, Maiti M, Das S, Basub R, Nandy P. Green synthesis of zinc oxide nanoparticles using
Hibiscus subdariffa leaf extract: effect of temperature on synthesis, anti-bacterial activity and anti-diabetic activity. RSC Adv 2015;5:4993-5003.

35. Acharyulu NPS, Madhu Kiran P, Pratap K, Kalyani RL, Pammi SVN. Room temperature synthesis and evaluation of antibacterial activity of silver nanoparticles using Phyllanthus amarus leaf extract. J Bionanosci 2014;8(3):190-4.

36. Kumar SN, Kumar NE, Priya P, Soni D, Vimalan M, Potheher IV. Synthesis, Anti-bacterial, Anti-arthritic, Anti-oxidant and In-vitro Cytotoxicity Activities of $\mathrm{ZnO}$ Nanoparticles Using Leaf Extract of Tectona grandis (L.). New J Chem 2017;41:10347-56.

37. Banu SK, Cathrine L. General Techniques Involved in Phytochemical Analysis. Int J Adv Res Chem Sci 2015;2(4): 25-32.

38. Aqeel Y, Siddiqui R, Anwar A, Shah MR, Khan NA. Gold Nanoparticle Conjugation Enhances the Antiamoebic Effects of Chlorhexidine. Antimicrob Agents Chemother 2015;60(3):1283-8.

39. Anna M, Oksana V, Jana K. Effect of chemically and biologically synthesized Ag nanoparticles on the algae growth inhibition. AIP Conference Proc 2017;1918:020008.

40. Tyagi PK, Tyagi S, Verma C, Rajpal A. Estimation of toxic effects of chemically and biologically synthesized silver nanoparticles on human gut microflora containing Bacillus subtilis. J Toxicol Environ Health Sci 2013;5(9):172-7.

41. Vasanth SB, Kuria GA. Toxicity evaluation of silver nanoparticles synthesized by chemical and green route in different experimental models Artificial Cells. Nanomed Biotechnol Int J 2017;45(8):1721-7.

42. De Lima R, Seabra AB, Durán N. Silver nanoparticles: a brief review of cytotoxicity and genotoxicity of chemically and biogenically synthesized nanoparticles. J Appl Toxicol 2012;32(11):867-79. 